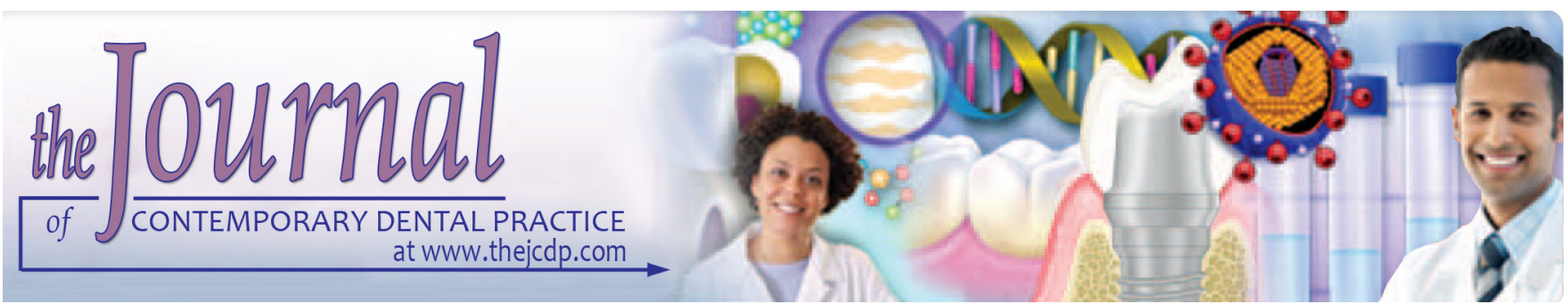

\title{
Clinical Significance of the Floral Shift in Candidiasis
}

\author{
${ }^{1} \mathrm{~A}$ Thirumal Raj, ${ }^{2}$ Shankargouda Patil, ${ }^{3}$ Govindarajan Sujatha, ${ }^{4}$ Charannya Seetharam, ${ }^{5}$ Nourah A Kader
}

Keywords: Antifungal agents, Azoles, Candida, Candidiasis,
Drug resistance, Fungal

How to cite this article: Raj AT, Patil S, Sujatha G, Seetharam C, Kader NA. Clinical Significance of the Floral Shift in Candidiasis. The Journal of Contemporary Dental Practice, October 2018;19(10):1161-1162.

\section{Source of support: Nil}

\section{Conflict of interest: None}

Candida albicans were the most commonly isolated candidal species in candidiasis. The past few decades have seen a gradual floral shift with many non-candida albican species including C. glabrata, C. dubliniensis, C. krusei, C. tropicalis, C. parapsilosis, and C. Kefyr being isolated at greater proportions. ${ }^{1}$ The clinical significance of such epidemiological shift is based on the inherent resistance of these non-C. albicans species to common antifungal agents. Recent studies have shown that non-candida albicans exposed to an even minimal dosage of azoles, especially fluconazole, can acquire resistance through upregulation of genes involved in drug metabolism and elimination. ${ }^{2}$ Thus, prolonged exposure to anti-fungal would increase the risk of developing resistance. Evidence for the same can obtained from recent studies showing a drastic increase in the prevalence of non-C. albicans species in cases with prolonged exposure to fluconazole. ${ }^{3}$ An alternative explanation for the increased isolation of

\footnotetext{
${ }^{1,3}$ Department of Oral Pathology and Microbiology, Sri Venkateswara Dental College and Hospital, Chennai, Tamil Nadu, India.

${ }^{2}$ Department of Maxillofacial Surgery and Diagnostic Sciences, Division of Oral Pathology, College of Dentistry, Jazan University, Jazan, Kingdom of Saudi Arabia

${ }^{4,5}$ All Smiles Dental Clinic, Besant Nagar, Chennai, India

Corresponding Author: A Thirumal Raj, Department of Oral Pathology and Microbiology, Sri Venkateswara Dental College and Hospital, Chennai, Tamil Nadu, India. Phone: +91 8122627810, email: thirumalraj666@gmail.com
}

non-C. albicans species, especially $C$. dubliensis could be explained by its phenotypical resemblance to $C$. albicans. Thus, many isolates of lesser-known C. dubliensis could have been identified in the past as C. albicans. The recent development of highly sensitive diagnostic tools could have aided in the accurate identification of $C$. dubliniensis which in turn could be misinterpreted as an increase in its prevalence. ${ }^{4}$

Nevertheless, there is an epidemiological shift in candida flora with a predominance of non-C. albicans species resulting in increasing cases of antifungal resistance. Thus, future research must focus on developing antifungal agents capable of overcoming the resistance of non-C. albicans. At present, amphotericin B, nystatin and caspofungin have proven to be relatively more effective against non-C. albicans than commonly used azoles. Despite its effectiveness nystatin, has a poor systemic absorption that limits its use to the local application. Thus, polyene antifungals like amphotericin $\mathrm{B}$ and second generation caspofungin are being promoted as the primary antifungals for candidiasis that are predominated by non-C. albican species. ${ }^{3}$ Voriconazole is another anti-fungal which has shown promising results against azole-resistant candidal species. ${ }^{5}$ In addition to developing novel anti-fungal agents, it is of utmost importance to curb the increasing use of azoles for longer durations as this is the main causefor the development of drug resistance. Apart from mainstream antifungals, recent studies are evaluating the use of other substances with anti-fungal effects. Trachyspermum ammi essential oil was found to be effective against all C. albicans isolates including fluconazole-resistant strains with a significant decrease in growth during the exponential phase. The oil also hampered with candida re-growth, reducing the refractory time. ${ }^{6}$

To conclude, given the epidemiological shift in candidal flora, it is vital to develop novel anti-fungal agents capable of overcoming the growing resistance of non-C. albican species. Also, it is of utmost importance 
that clinicians curb the liberal use of common antifungals as it is the leading cause for the development of resistance in both C. albicans and non-C. albicans species.

\section{REFERENCES}

1. Patel PK, Erlandsen JE, Kirkpatrick WR, Berg DK, Westbrook SD, Louden C et. al. The Changing Epidemiology of Oropharyngeal Candidiasis in Patients with HIV/AIDS in the Era of Antiretroviral Therapy. Hindawi Publishing Corporation AIDS Research and Treatment. 2012. doi:10.1155/2012/ 262471

2. A. Borst, M. T. Raimer, D. W. Warnock, C. J. Morrison, and B. A. Arthington-Skaggs, "Rapid acquisition of stable azole resistance by Candida glabrataisolates obtained before the clinical introduction of fluconazole," Antimicrobial Agents andChemotherapy. 2005; 49:783-787.
3. Katiraee F, Teifoori F, Soltani M. Emergence of azole-resistant Candida species in AIDS patients with oropharyngeal candidiasis in Iran. Curr Med Mycol. 2015;1:11-16.

4. W. R. Kirkpatrick, S. G.Revankar, R. K. McAtee, et al, “Detection of Candida dubliniensisin oropharyngeal samples from human immunodeficiency virus-infected patients in North America by primary CHROMagar Candida screening and susceptibility testing of isolates," Journal of Clinical Microbiology. 1998;36:3007-3012.

5. Anwar Khan P, Malik A, Subhan Khan H; Profile of candidiasis in HIV infected patients; Indian Journal of Microbiology. 2012;4:204-209.

6. Sharifzadeh A, Khosravi AR, Shokri H, Sharafi G. Antifungal effect of Trachyspermumammi against susceptible and fluconazole-resistant strains of Candida albicans. Journal De MycologieMédicale. 2015. 